\title{
THE ELECTROCHEMICAL BEHAVIOUR OF Al-Zn-In AND Al-Zn-Hg ALLOYS IN AQUEOUS HALIDE SOLUTIONS
}

\author{
C. B. Bresilin, L. P. Friery and W. M. Carroll* \\ Department of Chemistry, St Patrick's College, Maynooth, Co. Kildare, Ireland \\ * Department of Chemistry, University College, Galway, Ireland
}

\begin{abstract}
The electrochemical behaviour of $99.99 \%$ aluminium, an $\mathrm{Al}-\mathrm{Zn}-\mathrm{In}$ and $\mathrm{Al}-\mathrm{Zn}-\mathrm{Hg}$ alloy was investigated, and compared, in aqueous halide, sulphate and perchlorate solutions using electrochemical and surface analytical techniques. Localized attack was observed for pure aluminium and the two alloys (but at more electronegative potential values) in chloride, bromide, iodide and perchlorate solutions but attack of the mercury-containing alloy was observed, also, in sulphate and fuoride solutions. This was attributed to the additional effects of oxide detachment induced by mercury giving rise to large potential oscillations, approaching potential values close to the theoretical potential of aluminium, for immersion in sulphate solutions. The precipitation of oxyfluoride complexes in fluoride solutions leads to the observation of more passive behaviour in fluoride media. The major difference, in the electrochemical behaviour of pure aluminium and the alloys, lay in the extent of metastable attack, as evidenced by the higher frequency of current and potential fluctuations observed with the alloys, before complete breakdown of the passive films occurred.
\end{abstract}

\section{INTRODUCTION}

THE EFFEcTs of zinc, indium, gallium, mercury and tin as alloying elements on the corrosion behaviour of aluminium in aqueous chloride solutions are well known. ${ }^{1-6}$ These elements, alloyed with aluminium under the proper conditions, have the ability to activate aluminium, ensure its uniform dissolution and avoid polarization during dissolution. Most studies on these systems have concentrated, solely, on producing aluminium-based anodes capable of operating efficiently in cathodic protection systems or power sources. ${ }^{7-10}$ Consequently fundamental studies on the electrochemical behaviour of these alloys have been completed only rarely and when related studies have been carried out they have been concerned, mainly, with the effects of activator salts, in solution, on the electrochemical activity of pure aluminium. . $^{2,5,6}$

It is well known that zinc, in combination with other activator elements, alloyed with aluminium can produce efficient sacrificial anodes. ${ }^{1,2,9}$ The studies conducted in this area have been concerned, largely, with the optimisation of the current output and efficiency of these tertiary activated anodes. Some mechanistic studies have been conducted to account for the effects of activator elements on aluminium, and although these studies have been specifically carried out with zinc, the authors, generally, have extended their proposed mechanisms to all activator elements. Some fundamental studies have been carried out on the effects imparted by zinc alone, when alloyed with aluminium. In these studies, the investigators have compared zinc 
with elements such as chromium, molybdenum and tungsten. The models proposed to account for the pitting behaviour of homogenous $\mathrm{Al}-\mathrm{Zn}$ alloys have included the $\mathrm{pH}$ of zero charge mode ${ }^{11}$ for pit initiation, acidification model, ${ }^{12}$ the acid solution solubility model ${ }^{13}$ and micro-tunnelling model. ${ }^{14}$ These studies have been conducted primarily to advance the understanding of the pitting process.

In this communication the previous studies carried out with zinc as an alloying component are extended to tertiary alloys: $\mathrm{Al}-\mathrm{Zn}-\mathrm{In}$ and $\mathrm{Al}-\mathrm{Zn}-\mathrm{Hg}$ alloys. The electrochemical behaviour and surface morphology of these alloys in aqueous halide solution is described and discussed. The findings are compared to the current models of pit initiation of pure aluminium and the proposed mechanisms to account for the activation of aluminium by activator elements in an attempt to connect these two processes, previously approached from different viewpoints, in a unified model.

\section{EXPERIMENTAL METHOD}

The pure aluminium electrodes, of dimensions $1 \times 20 \times 20 \mathrm{~mm}$, used in this work were cut from $99.99 \%$ aluminium sheet. The aluminium alloy electrodes, of dimensions $3 \times 30 \times 20 \mathrm{~mm}$, were cut from $\mathrm{Al}-3.5 \mathrm{Zn}-0.02 \mathrm{In}$ and $\mathrm{Al}-3.5 \mathrm{Zn}-0.04 \mathrm{Hg}$ respectively. These alloys were fabricatd from $99.95 \%$ aluminium and were used in the cast state. The concentrations of indium and mercury were maintained at, or below, the solubility limits of indium and mercury in aluminium so as to avoid the presence of second phase indium and mercury precipitates. All samples were abraded with $\mathrm{SiC}$ paper to a grit finish of 1000 , were washed in distilled water and methanol and, then, were mounted in a beeswax-colophony resin (mixed in a ratio 1:3) so as to expose a circular working electrode surface $1 \mathrm{~cm}^{2}$ in area.

Potentiodynamic polarization measurements were made using an EG\&G Versastat controlled by the model 342 corrosion-measurement-software package. The aluminium electrodes were polarized at $-1.8 \mathrm{~V}(\mathrm{SCE})$ in the cell electrolyte for a 1 -min period and then subjected to a voltage scan of $1 \mathrm{mV} \mathrm{s}^{-1}$. The scan was terminated when the current associated with film breakdown exceeded a value of $70 \mu \mathrm{A} \mathrm{cm}{ }^{-2}$. The polarization period at $-1.8 \mathrm{~V}$ ensured an essentially oxide-free reproducible surface in each experiment and induction periods prior to the onset of activity in the alloy systems were avoided. The charge passed during this period varied from 2.0 to $3.0 \mathrm{mC} \mathrm{cm}^{-2}$.

Extended potentiostatic current-time measurements were carried out with a Thompson Precision potentiostat, the current being measured by recording the potential drop across a standard resistor on an $x-t$ recorder. The working electrodes were polarized at $-1.8 \mathrm{~V}(\mathrm{SCE})$ for a 2 -min period in the working solution, then the desired polarization potential was applied and the current was recorded as a function of time. The electrochemical cell consisted of a Pyrex glass cell, graphite auxiliary electrodes and a saturated calomel reference electrode (SCE). All solutions were prepared from AnalaR grade reagents and distilled water. The $\mathrm{pH}$ of the test solutions was adjusted to the desired values by the addition of $\mathrm{NaOH}$ or the appropriate acids, $\mathrm{HCl}, \mathrm{HBr}, \mathrm{HI}$ and $\mathrm{HF}$.

In activation initiation studies the specimens were polarized at $-1.8 \mathrm{~V}$ for a $2-m i n$ period in a $0.5 \mathrm{M}$ $\mathrm{NaCl}$ solution and then polarized at the required potential for a 25 -min period in the same solution. Sufficient amounts of dissolved indium sulphate in a $0.5 \mathrm{M} \mathrm{NaCl}$ electrolyte were then added to the original electrolyte to give the required concentration of indium in solution. The resultant solution was agitated with nitrogen to ensure rapid mixing. The current was measured as a continuous function of time. The induction period, $\tau$, was deemed to be the time interval between the addition of the activator and the onset of the current increase in the potentiostatic measurements.

Suitable surface areas of the corroded specimens were examined using a Hitachi scanning electron microscope operating in a secondary-electron image mode, with accelerating voltages of $20 \mathrm{kV}$. Elemental compositions of surface regions were analysed using the Link 1000 EDAX unit (energy dispersive Xray analyses) coupled to the SEM.

\section{EXPERIMENTAL RESULTS}

The polarization behaviour of $99.99 \%$ aluminium, $\mathrm{Al}-\mathrm{Zn}-\mathrm{In}$ and $\mathrm{Al}-\mathrm{Zn}-\mathrm{Hg}$ alloys in $0.5 \mathrm{M}$ halide solutions was investigated. The potentiodynamic polarization 


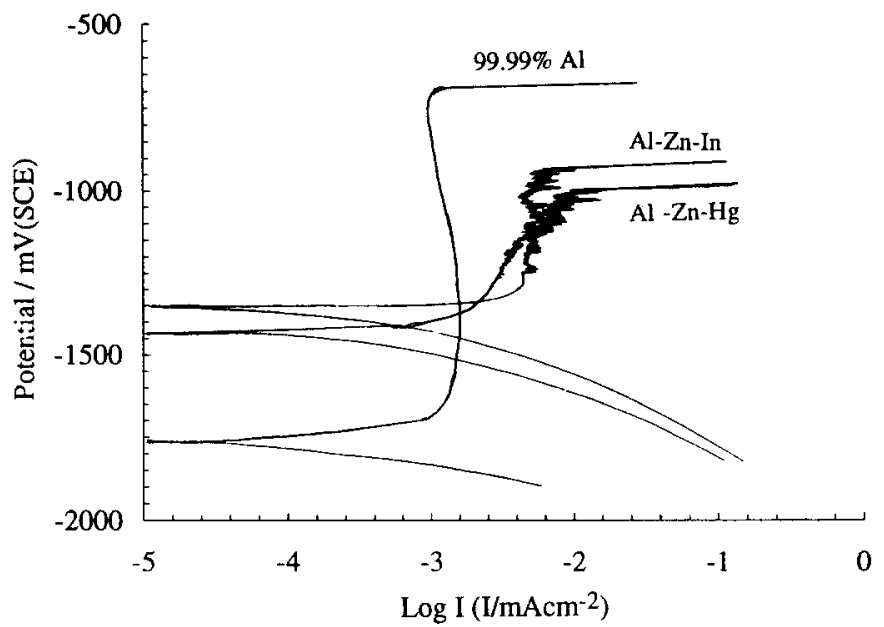

Fig. 1. Potentiodynamic polarization plots for $99.99 \% \mathrm{Al}, \mathrm{Al}-\mathrm{Zn}-\mathrm{In}$ and $\mathrm{Al}-\mathrm{Zn}-\mathrm{Hg}$ polarized from $-1800 \mathrm{mV}(\mathrm{SCE})$ at a rate of $1 \mathrm{mV} \mathrm{s}^{-1}$ in a neutral $0.5 \mathrm{M} \mathrm{NaCl}$ solution.

curves of these three materials in $0.5 \mathrm{M} \mathrm{NaCl}$ solution are shown in Fig. 1. The polarization curve obtained with pure aluminium shows the usual passive characteristics of the metal; a passive current density of the order of $1 \mu \mathrm{A} \mathrm{cm}{ }^{-2}$ and a sharp current increase at $-710 \mathrm{mV}(\mathrm{SCE})$ which indicates the onset of pitting, or localized, attack. The passive currents recorded for the two alloys are an order of magnitude greater than that obtained with the pure metal, but the most striking effects of alloying are the shift in the breakdown potentials in the cathodic direction and the onset of current fluctuations, prior to stable pit growth, at potentials more electropositive than $-1300 \mathrm{mV}(\mathrm{SCE})$.

Similar behaviour was observed in bromide and iodide solutions with more electropositive breakdown potentials being recorded when the chloride anion was replaced by the less aggressive bromide and iodide anions. The breakdown potentials as a function of the nature of the aggressive anion for the alloys and pure metal are shown in Table 1. The behaviour of the indium-containing alloy did not differ markedly from that of the pure aluminium. Localized attack was observed with both electrodes in chloride, bromide, iodide and perchlorate solutions only. The mercury-

TAble 1. Pimting potentials of $99.99 \% \mathrm{Al}, \mathrm{Al}-\mathrm{Zn}-\mathrm{In}$ ANd Al-Zn$\mathrm{Hg}$ in $0.5 \mathrm{M}$ SOLutions

\begin{tabular}{lccc}
\hline & \multicolumn{3}{c}{ Pitting potential (mV(SCE)) } \\
\cline { 2 - 4 } $0.5 \mathrm{MX}$ & $99.99 \% \mathrm{Al}$ & $\mathrm{Al}-\mathrm{Zn}-\mathrm{In}$ & $\mathrm{Al}-\mathrm{Zn}-\mathrm{Hg}$ \\
\hline $\mathrm{Cl}^{-}$ & -715 & -958 & -1005 \\
$\mathrm{Br}^{-}$ & -570 & -807 & -990 \\
$\mathrm{I}^{-}$ & -455 & -530 & -945 \\
$\mathrm{~F}^{-}$ & - & - & $-450-+100$ \\
$\mathrm{ClO}_{4}^{-}$ & -215 & -555 & -810 \\
$\mathrm{SO}_{4}^{2-}$ & - & - & -710 \\
\hline
\end{tabular}




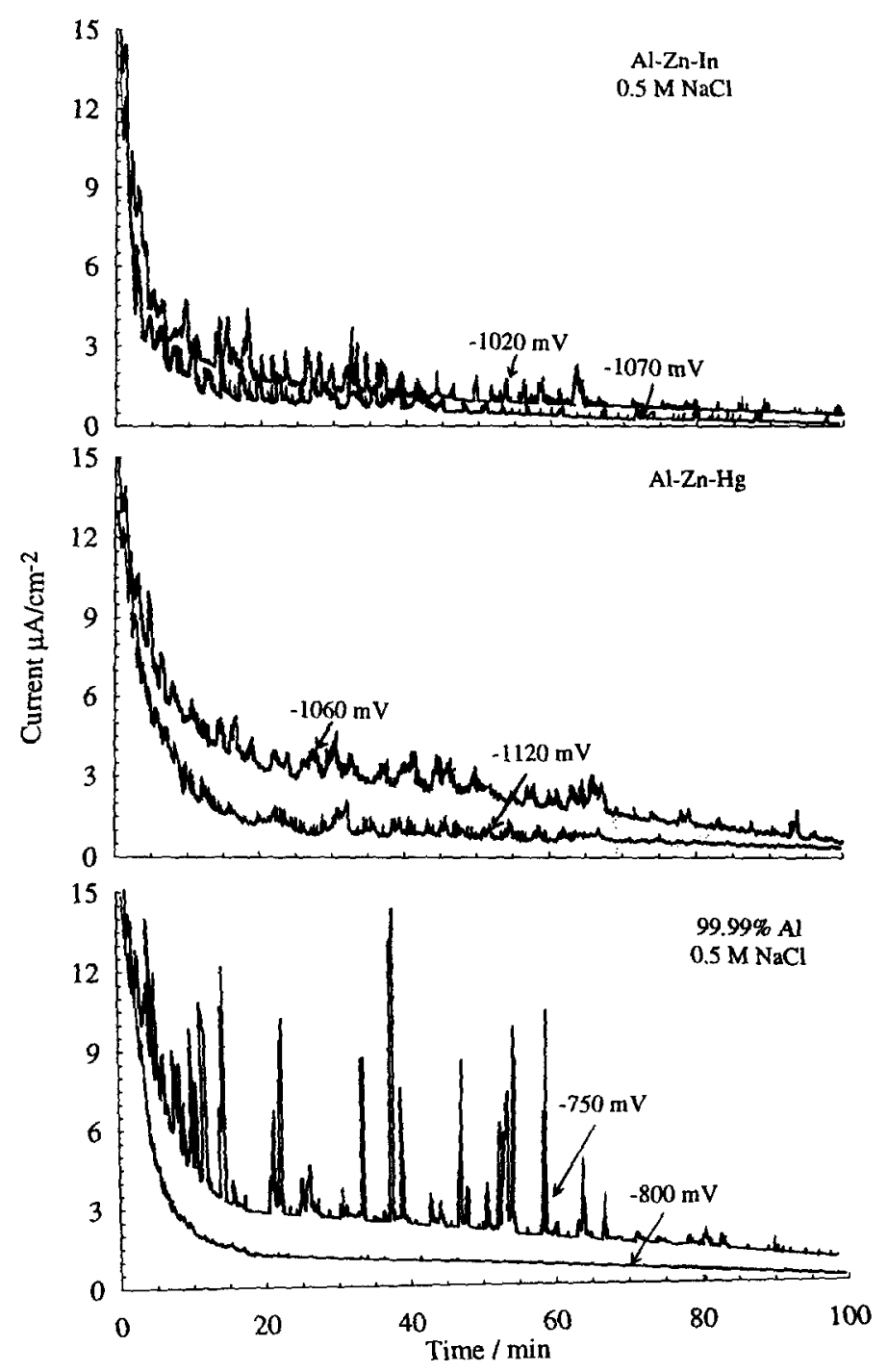

Fig. 2. Top: Potentiostatic current-time plot for $\mathrm{Al}-\mathrm{Zn}$-In polarized at applied potentials of -1020 and $-1070 \mathrm{mV}(\mathrm{SCE})$ in a neutral $0.5 \mathrm{M} \mathrm{NaCl}$ solution; Centre: Potentiostatic current-time plot for $\mathrm{Al}-\mathrm{Zn}-\mathrm{Hg}$ polarized at applied potentials of -1060 and $-1120 \mathrm{mV}(\mathrm{SCE})$ in a neutral $0.5 \mathrm{M} \mathrm{NaCl}$ solution; Bottom: Potentiostatic current-time plot for $99.99 \%$ Al polarized at applied potentials of -750 and $-800 \mathrm{mV}$ (SCE) in a neutral $0.5 \mathrm{M} \mathrm{NaCl}$ solution.

containing alloy showed active behaviour in sulphate and fluoride solutions. In the presence of fluoride anions the current fluctuated on polarizing the electrode in the electropositive direction indicating metastable activation repassivation events in the potential range -450 to $+100 \mathrm{mV}(\mathrm{SCE})$.

Potentiostatic current-time and open circuit potential-time measurements showed clearly the onset of metastable activation repassivation events in aggressive solutions for both alloy materials. In Fig. 2, the current-time behaviour of A1- $\mathrm{Zn}-$ 
In, $\mathrm{Al}-\mathrm{Zn}-\mathrm{Hg}$ and pure aluminium, in a $0.5 \mathrm{M} \mathrm{NaCl}$ solution, as a function of the applied potential, are shown. Stable pit development is observed on pure aluminium at applied potentials of $-710 \mathrm{mV}(\mathrm{SCE})$. Under applied potential conditions of $-750 \mathrm{mV}$ current fluctuations dominate the current decay profile, particularly in the early stages of film growth. The decay profile recorded at $-800 \mathrm{mV}$, only $50 \mathrm{mV}$ more electronegative than potential conditions that promote metastable pitting attack, is completely free from any oscillations or fluctuations, which indicates passive film formation. On the other hand, fluctuations continue to dominate the decay profiles recorded for the indium and mercury-containing alloys even at potentials that are greater than $100 \mathrm{mV}$ removed from the potential, which corresponds to stable pit development. This indicates a much wider potential range in which activation-repassivation events occur. In all cases with prolonged polarization, the frequency and magnitude of the fluctuations decreased, which was indicative of a film-improvement type reaction in which the surface was modified to render it less susceptible to metastable pitting attack. Similar effects are observed in open circuit potential time measurements for the alloys in aggressive solutions.

In Fig. 3, the potential transients over a $10-$ min period (recorded after a $25-\mathrm{min}$ immersion period in the aggressive solution) are shown as a function of the electrode composition and anion type. Potential fluctuations are observed in all experiments, however, the magnitude of the fluctuations depends, significantly, on the electrode material. Potential fluctuations, which span over a $20 \mathrm{mV}$ range, are observed with pure aluminium in all halide solutions other than fluoride. For both alloy materials fluctuations extend over a $100 \mathrm{mV}$ range in chloride, bromide and iodide solutions. In addition, attack of the mercury-containing alloy in sulphate and fluoride solutions is evident from the potential oscillations which extend over several hundred millivolts in the sulphate solution.

The surface morphology of pure aluminium and the Al-Zn-In alloy specimens polarized to the pitting potential in a $0.5 \mathrm{M} \mathrm{NaCl}$ solution are shown in Fig. 4(a) and (b) respectively. These test specimens were polarized from $-1.8 \mathrm{~V}(\mathrm{SCE})$ up to the pitting potential at a scan rate of $1 \mathrm{mV} \mathrm{s}^{-1}$. The scan was terminated when the pitting

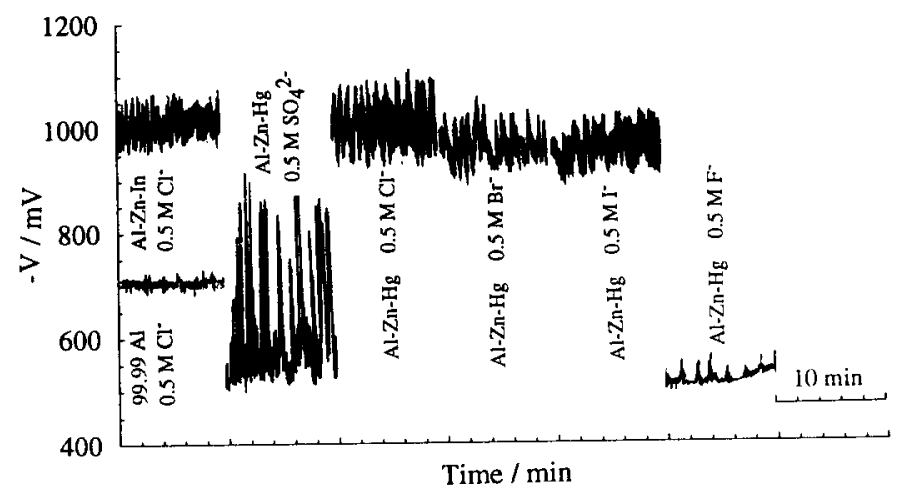

FIG. 3. Open circuit potential-time transients of $99.99 \% \mathrm{Al}$ in $0.5 \mathrm{M} \mathrm{NaCl}$ solution; $\mathrm{Al}-\mathrm{Zn}-\mathrm{In}$ in $0.5 \mathrm{M} \mathrm{NaCl}$ solution; $\mathrm{Al}-\mathrm{Zn}-\mathrm{Hg}$ in $0.5 \mathrm{M} \mathrm{Na}_{2} \mathrm{SO}_{4}$ solution; $\mathrm{Al}-\mathrm{Zn}-\mathrm{Hg}$ in $0.5 \mathrm{M} \mathrm{NaCl}$ solution; $\mathrm{Al}-\mathrm{Zn}-\mathrm{Hg}$ in $0.5 \mathrm{M} \mathrm{NaBr}$ solution; $\mathrm{Al}-\mathrm{Zn}-\mathrm{Hg}$ in $0.5 \mathrm{M}$ Nal solution and $\mathrm{Al}-\mathrm{Zn}-\mathrm{Hg}$ in $0.5 \mathrm{M} \mathrm{NaF}$ solution. Potential transients recorded over a 10 -min interval following an initial 25 -min immersion period in the test solution. 
current density reached a value of $100 \mu \mathrm{A} \mathrm{cm}^{-2}$. Well developed pits are observed for the pure aluminium sample, but for the alloy only pits in the early stages of development are observed. These have a tendency to form in clusters, evident in the lower right hand side in Fig. 4(b). The surface morphology of the mercury-containing alloy was very similar to the indium-containing alloy on polarizing from $-1.8 \mathrm{~V}$ up to the pitting potential; the pits were in the early stages of development, only, and appeared to form in clusters.

In many other aspects, the electrochemical behaviour of the alloys did not differ significantly from that of the pure aluminium metal. In all cases a linear dependence of the pitting potential on the logarithm of the chloride concentration in the bulk solution was valid for aluminium and the two alloys. A graphical representation indicating this dependence is shown in Fig. 5. The slopes of the lines, $\mathrm{d} E_{\mathrm{pitt}} / \mathrm{dlog}\left[\mathrm{Cl}^{-}\right]$, were essentially constant for the three systems, the derivative for pure aluminium being in good agreement with previous reports. ${ }^{15-17}$

The dependence of the pitting potential on the bulk solution $\mathrm{pH}$ was similar, again for the three materials. These relationships obtained in a $0.5 \mathrm{M} \mathrm{NaCl}$ solution are shown in Fig. 6. The pitting potentials remain independent of $\mathrm{pH}$ up to a $\mathrm{pH}$ value of approximately 9.0 at which point more noble breakdown potentials are recorded.

The process by which indium, dissolved as salt in solution, is deposited, in metallic form, at the surface of the pure aluminium and $\mathrm{Al}-\mathrm{Zn}$-In electrodes (studied by using the activation initiation studies described above in the Experimental section) gave similar effects with both systems. The induction periods were measured as the time interval between the addition of the indium salt solution to the working electrolyte and the current increase which signified the onset of activation. A typical activation plot is shown in Fig. 7 for the activation of pure aluminium passivated at $-1050 \mathrm{mV}(\mathrm{SCE})$ in a $0.5 \mathrm{M} \mathrm{NaCl}$ solution for a $25-\mathrm{min}$ period by the addition of a $0.01 \mathrm{M}$ indium sulphate solution. Similar activation plots, but with slightly fewer activation-repassivation events, were obtained for the alloy, but a lower concentration of the indium salt solution was required to achieve activation in a comparable time span. In Fig. 8, the measured induction periods are presented as a function of the applied potential to the working electrodes. For the pure aluminium samples a $0.01 \mathrm{M}$ indium salt solution was added to the working electrolyte, while a $0.005 \mathrm{M}$ indium salt concentration was added with the alloy. Because of the statistical nature of the onset of activation, each activation experiment was repeated at least three times and thus the induction periods shown are an average of at least three experiments. In both cases, it is seen that the induction periods reach a minimum at applied potentials in the region of -1000 to $-1100 \mathrm{mV}$ and that the induction periods increase significantly with the application of more electropositive potentials.

\section{DISCUSSION}

The results presented in this communication show that the electrochemical behaviour of pure aluminium, the mercury-containing alloy and the indiumcontaining alloy in chloride, bromide, iodide and perchlorate solution are similar. The major difference lies in the extent of metastable attack, as evidenced by the higher frequency of current and potential fluctuations or oscillations (Figs 1,2 and 3) before complete breakdown of the passive film occurs.

There have been various reports in the literature over the years as regards the 

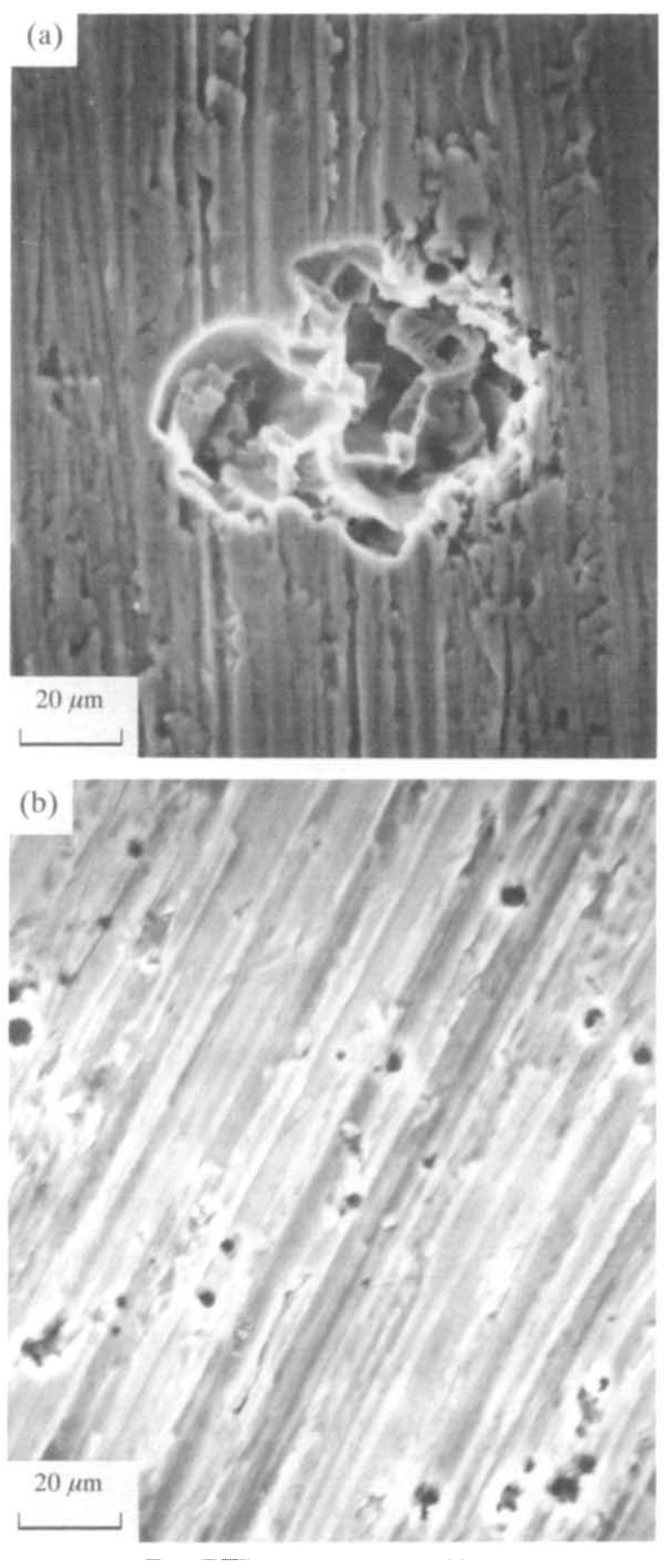

Fig. 4. (a) SEM micrograph of the surface of $99.99 \% \mathrm{Al}$ polarized to the pitting potential in $0.5 \mathrm{M} \mathrm{NaCl}$ solution; (b) SEM micrograph of the surface of $\mathrm{Al}-\mathrm{Zn}-\mathrm{In}$ polarized to the pitting potential in $0.5 \mathrm{M} \mathrm{NaCl}$ solution. 

significance and origin of these fluctuations on current decay and potential profiles. $^{18-22}$ Okamato $^{18}$ attributed the small irregular patterns observed for prepassivated $18-\mathrm{Cr}-\mathrm{Ni}$ steel, after the addition of chloride, to a competitive process between breakdown and repair at the steel surface before the final domination of the breakdown process leading to a steady increase in current. Wood and co-workers ${ }^{19}$ considered a number of explanations including the evolution of gas, changes in the relative cathodic and anodic areas with time, and the competition between local activation and repassivation events, in a crack-heal pit initiation mechanism. These oscillations were found to depend, in all cases, on both the properties of the passive film and the electrolyte composition and could be used as an indicator of passive film stability.

The crack-heal mechanism for pit initiation advanced by Wood and co-workers in the 1970s has received strong conformation from a number of investigations. ${ }^{23,24}$ It would be expected that the transient exposure of bare aluminium to the solution in a repeated cycle of cracking and healing steps would give rise to oscillations in both current and potential measurements. The higher frequency of oscillations observed with the alloys lend support to a recent suggestion ${ }^{25}$ that the presence of zinc promotes the nucleation of $\mathrm{ZnAl}_{2} \mathrm{O}_{4}$ spinel. The molar volume of this naturally occurring aluminate, $39.78 \mathrm{~cm}^{3}$, is greater than the corresponding molar volumes of aluminium oxide, $25.57 \mathrm{~cm}^{3}$, boehmite, $19.50 \mathrm{~cm}^{3}$ or diaspore, $17.76 \mathrm{~cm}^{3}$; boehmite and diaspore being hydrated forms of aluminium and consequently approximate more closely the true hydrated nature of the electrode in aqueous solution. Thus the nucleation of zinc-aluminium spinel should give rise to increased cracking of the protective layer. The formation of a zinc-aluminium spinel is suggested, as opposed to indium-aluminium or mercury-aluminium oxide structures, because of favoured stability and the fact that a similar degree of instability with $\mathrm{Al}-\mathrm{In}, \mathrm{Al}-\mathrm{Hg}$ or Al-Ga alloys under similar conditions has not been observed. ${ }^{26}$ Indeed, the significant effect of the perchlorate anion in displacing the breakdown potentials in the electronegative direction (Table 1) may be associated with the fact that this much larger anion can come into direct contact with the bare exposed surface during the cracking and healing cycle. The extent of displacement of the pitting potential in these perchlorate solutions seems too high for the effect to be associated with the presence of chloride ions in perchlorate solutions as suggested in some works. ${ }^{27}$

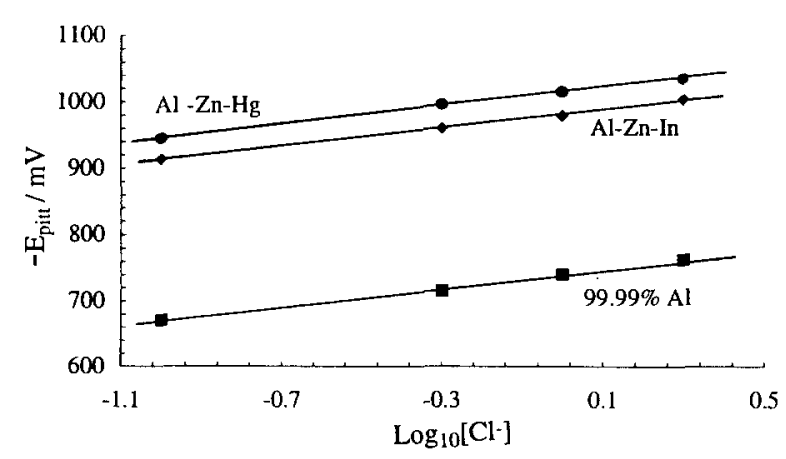

Fig. 5. Pitting potential $/ \mathrm{mV}$ as a function of the logarithm of the chloride concentration for $99.99 \% \mathrm{Al}, \mathrm{Al}-\mathrm{Zn}-\mathrm{In}$ and $\mathrm{Al}-\mathrm{Zn}-\mathrm{Hg}$. 


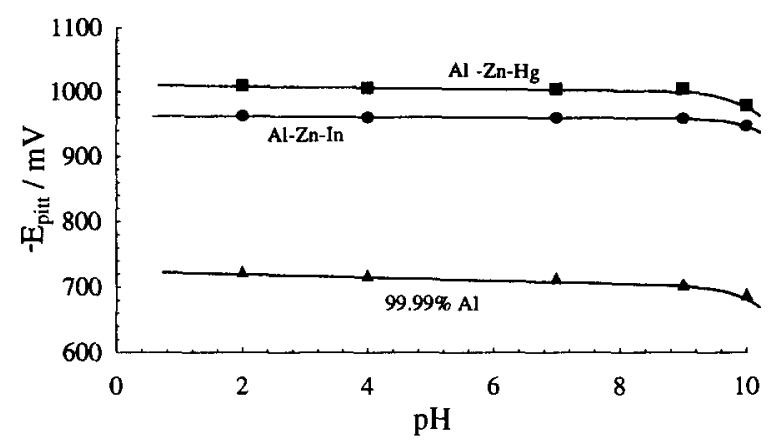

Fig. 6. Pitting potential $/ \mathrm{mV}$ as a function of the $\mathrm{pH}$ of a $0.5 \mathrm{M} \mathrm{NaCl}$ solution for $\Delta$ $\mathbf{9 9 . 9 9 \% ~ A l , ~} \mathrm{Al}-\mathrm{Zn}-\mathrm{In}$ and $\mathrm{Al}-\mathrm{Zn}-\mathrm{Hg}$.

The large number of pits in the early stages of development observed with the Al-Zn-In alloy (Fig. 4) are in line with the small, but frequent, fluctuations observed on the current-decay profiles. This surface attack is quite similar, in some respects, to that observed by Kaesche for $\mathrm{Al}-\mathrm{Zn}$ homogenous alloys ${ }^{14}$ in which pitting attack in the $\mathrm{Al}-\mathrm{Zn}$ alloys is viewed as tunnel nucleation at sites where pitting has already started. In this study, too, there is evidence of clustering and indeed pit initiation may be preferred at sites where attack has already been initiated over sites on the uncorroded surface giving rise to autocatalytic-like attack. An autocatalytic mechanism has been suggested, ${ }^{2}$ previously, to account for the activity of mercury and indium-activated aluminium in which dissolution of the anode introduces both aluminium and activator ions into solution with the activator species being deposited, subsequently, at the surface, giving rise to further dissolution of the anode. This phenomenon may lead to the clustering effects observed in this study. On the other hand, the presence of the much larger fluctuations observed with pure aluminium (Fig. 2) are in agreement with the deeper and more developed pits formed on the pure aluminium surface (Fig. 4).

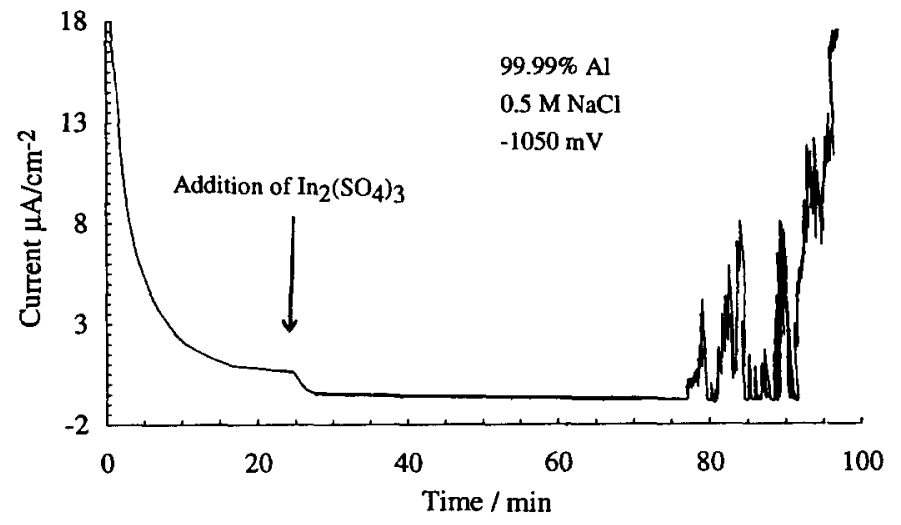

Fig. 7. Current-time activation plot for $99.99 \% \mathrm{Al}$ passivated at $-1050 \mathrm{mV}(\mathrm{SCE})$ in a neutral $0.5 \mathrm{M} \mathrm{NaCl}$ solution. After a 25 -min passivation period a $0.01 \mathrm{M} \mathrm{In}_{2}\left(\mathrm{SO}_{4}\right)_{3}$ solution is added. 


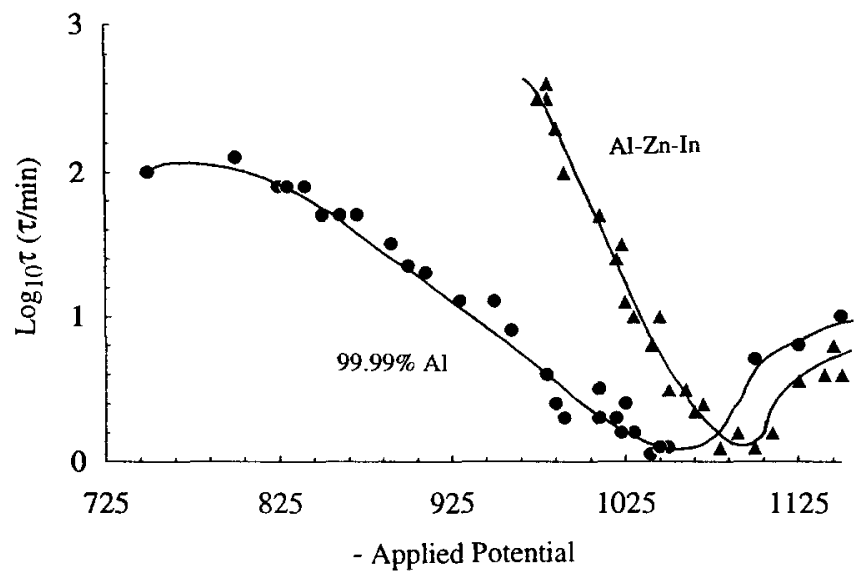

FIG. 8. The logarithm of the induction period, $\tau$, measured for the activation of $99.99 \%$ $\mathrm{Al}$ and $\mathrm{Al}-\mathrm{Zn}-\mathrm{In}$ in $0.5 \mathrm{M} \mathrm{NaCl}$ solution by a 0.01 and $0.005 \mathrm{M} \operatorname{In}_{2}\left(\mathrm{SO}_{4}\right)_{3}$ solution respectively, as a function of the potential $/ \mathrm{mV}$ applied to the electrodes.

The film-improvement effects, which rendered the electrode surface less susceptible to pitting attack, observed on prolonged passivation in the test solutions (Fig. 2 ), have previously been attributed to oxide transformation reactions for pure aluminium in chloride and bromide solutions. ${ }^{28,29}$ The adsorbed chloride, or halide, forms a series of oxyhydroxo and halo complexes with aluminium which are then transformed to $\alpha-\mathrm{Al}(\mathrm{OH})_{3}$ or the stable hydrated oxide $\gamma-\mathrm{Al}_{2} \mathrm{O}_{3} \cdot 3 \mathrm{H}_{2} \mathrm{O}$. These hydrated regions offer greater resistance to cracking events and to surface attack and thus the fluctuations diminish with prolonged passivation. It appears that similar events take place with the alloy materials, but longer periods of time are required to achieve comparable degrees of hydration and the ennoblement observed in the breakdown potential on immersing pure aluminium in chloride solutions for extended periods of time ${ }^{29}$ was not as pronounced with these alloy materials.

Even though this cracking process will allow the direct contact between the base metal and the aggressive anion it is not sufficient to initiate attack of the metal surface. The intensification of metastable attack with increasing potential (Fig. 2) and the dependence of the pitting potential on chloride concentration (Fig. 5) may indicate that the breakdown of the passive film is connected with the surface charge, where the influence of potential may be to move the surface above the point of zero charge, $E_{\mathrm{pzc}}$, and increasing halide concentration to move the $E_{\mathrm{pzc}}$ in the active direction. ${ }^{30}$ In this analysis, if the potential applied to the electrode is sufficiently noble to charge the surface positively with respect to the $E_{\mathrm{pzc}}$ then adsorption of the negatively charged chloride will occur at the metal surface. Alternatively, if the surface is negatively charged with respect to the $E_{\mathrm{pzc}}$ then protonated water molecules will be adsorbed at the surface giving rise to passive conditions.

The potential-induction period plots shown in Fig. 7 can be explained using similar surface-charge considerations. The initiation of activation in these experiments depends on the deposition of indium at flaws and defective centres in the passive film. ${ }^{2,31}$ It is to be expected that as the applied potential is increased in the anodic direction and the surface becomes progressively more positive, the rate of 
metal deposition at the surface would be repressed. This is reflected, in both plots, by the higher induction periods with increasing applied potential in the anodic direction. The somewhat lower induction periods observed at potentials close to the breakdown potentials of the systems may be connected to the fact that accelerated deposition of the activator species occurs at these potentials because of a greater flux of electrons for the required exchange reaction due to the greater interaction between chloride and the substrate metal at these potential conditions. ${ }^{32}$ If this line of reasoning is correct, then it appears that similar events occur with both pure aluminium and its alloy systems, the only variable being the potential of zero charge which is shifted in the electronegative direction for the alloys.

The breakdown of the mercury-containing electrode in sulphate and fluoride solutions is connected to the additional oxide-detachment effects ${ }^{2}$ induced by mercury. There is evidence to suggest that mercury can form an amalgam with aluminium, detach the passivating film and prevent further passive film formation. ${ }^{2}$ This could account for the large oscillations in the open circuit potential (Fig. 3), where the detachment of regions of the passive film could give conditions approaching that of bare aluminium attaining the theoretical electrode potential for aluminium. Even though the same events should occur in fluoride solutions the formation and precipitation of oxyfluoride complexes ${ }^{33}$ at the surface would reduce the activity of the electrode thereby explaining the minor fluctuations in the potential-time traces (Fig. 3), and the difficulties in obtaining a breakdown potential for the alloy in fluoride solutions. The presence of a much greater alloying concentration of zinc compared to that of mercury reduces, somewhat, the activity of the mercury component. Passive conditions are observed and the behaviour of the mercury-containing alloy appears similar to that of the indium-containing alloy under most experimental conditions.

\section{CONCLUSIONS}

It may be concluded from the above analyses that the mechanisms of film breakdown of pure aluminium and the aluminium-zinc-indium alloy are similar. The initiation step depends both on the availability of defective centres and on the adsorption of the aggressive anion at these areas which in turn depends on the surface charge character of the electrode. On polarizing the aluminium-zinc-indium alloy in the electropositive direction the potential of zero charge is reached at a much more electronegative potential than that observed with the pure metal and thus pit initiation is observed at lower applied potentials. A much greater frequency of cracking and healing steps occurs at the film-solution interface in the alloy systems and consequently a greater number of metastable activation repassivation events are observed before the surface charge density is such that it facilitates enhanced halide adsorption and stable pit development. The addition of mercury to the aluminiumzinc system increases the activity of the alloy in fluoride and in non-halide solutions.

\section{REFERENCES}

1. J. T. Reding and J. J. Newport, Matr. Protection 5, 15 (1966).

2. M. C. Reboul, Ph. Gimenez and J. J. Rameau, Corrosion 40, 366 (1984)

3. W. J. Bohnstedt, J. Power Sources 5, 245 (1980).

4. C. D. S. Tuck, J. A. Hunter and G. M. Scamans, J. electrochem. Soc. 134, 2070 (1987).

5. G. Burri, W. Leudi and O. HaAs, J. electrochem. Soc. 136, 2167 (1989).

6. C. B. Breslin and W. M. Carroll, Corros. Sci. 33, 1735 (1992). 
7. J. J. Batten, B. T. Moore and B. S. Smith, Mater. Forum 1, 69 (1992).

8. R. F. MAY, Proc. 7 th Australian Electrochem. Conf., Sydney, p. 279 (1988).

9. T. Sakano, K. Toda and M. Hanada, Mater. Protection 5, 45 (1966).

10. E. G. Haney and G. E. Kurr, Mater. Protection 15, 27 (1976).

11. P. M. Natishan, E. McCafferty and G. K. Hubler, J. electrochem. Soc. 133, 1061 (1986).

12. J. R. Galvele, J. electrochem. Soc. 123, 464 (1976).

13. Z. Szklarska-Smialowska, Proc. Symp. Crit. Factors Loc. Corros. 9, 311 (1992).

14. G. Knornschild and H. KaesChe, Proc. Symp. Crit. Factors Loc. Corros. 9, 266 (1992).

15. H. Bohn and H. H. UhLIG, J. electrochem. Soc. 116, 906 (1969).

16. J. R. Galvele and S. M. De Micheli, Corros. Sci. 10, 795 (1970).

17. F. Ovari, L. Tomcsanyi and T. Turmezey, Electrochim. Acta 33, 323 (1988).

18. G. Окамato, Corros. Sci. 13, 471 (1973).

19. G. C. Wood, W. H. Sutton, J. A. Richardson and C. JACkson, Localized Corrosion, p. 526. NACE, Houston, Texas (1974).

20. F. P. Ford, G. T. Burstein and T. P. Hoar, J. electrochem. Soc. 127, 1325 (1980).

21. M. Keddam, M. Krati and C. Pallotta, Corrosion 43, 454 (1987).

22. G. S. Frankel, L. Stockert, F. Hunkeler and H. Boehni, Corrosion 43, 429 (1987).

23. A. K. VIGH, Mater. Chem. Phys. 20,371 (1988).

24. J. R. Galvele, Corros. Sci. 21, 551 (1981).

25. C. B. Breslin and L. P. Friery, Corros. Sci. in press.

26. C. B. BresLin, unpublished results.

27. A. R. Despic, D. M. Drazic, S. K. Zecevic and R. T. Atanasoski, Electrochim. Acta 26, 173 (1981).

28. W. M. Carroll and C. B. Breslin, Br. Corros. J. 26. 255 (1991).

29. C. B. Breslin and W. M. Carroll, Corros. Sci. 34, 327 (1993).

30. R. J. Brigham, Corros. Sci. 29, 995 (1989).

31. W. M. Carroll and C. B. Breslin, Corros. Sci. 33, 1161 (1992).

32. J. Augustrnski, in Passivity of Metals (eds R. P. Frankenthal and J. Kruger), p. 989. Electrochemical Society, Pennington, New Jersey (1987).

33. W. M. Carroll, M. Murphy and C. B. Breslin, Corros. Sci. 34, 1495 (1993). 